\title{
A Longitudinal Study of How Quality Mentorship and Research Experience Integrate Underrepresented Minorities into STEM Careers
}

\section{Mica Estrada, ${ }^{* *}$ Paul R. Hernandez, ${ }^{*}$ and P. Wesley Schultz ${ }^{\S}$}

${ }^{\dagger}$ Department of Social and Behavioral Sciences, University of California, San Francisco, San Francisco, CA 94118; ‘Department of Learning Sciences and Human Development, West Virginia University, Morgantown, WV 26506; `Department of Psychology, California State University San Marcos, San Marcos, CA 92096

\begin{abstract}
African Americans, Latinos, and Native Americans are historically underrepresented minorities (URMs) among science, technology, engineering, and mathematics (STEM) degree earners. Viewed from a perspective of social influence, this pattern suggests that URMs do not integrate into the STEM academic community at the same rate as non-URM students. Estrada and colleagues recently showed that Kelman's tripartite integration model of social influence (TIMSI) predicted URM persistence into science fields. In this paper, we longitudinally examine the integration of URMs into the STEM community by using growth-curve analyses to measure the development of TIMIS's key variables (science efficacy, identity, and values) from junior year through the postbaccalaureate year. Results showed that quality mentorship and research experience occurring in the junior and senior years were positively related to student science efficacy, identity, and values at that same time period. Longitudinal modeling of TIMSI further shows that, while efficacy is important, and perhaps a necessary predictor of moving toward a STEM career, past experiences of efficacy may not be sufficient for maintaining longer-term persistence. In contrast, science identity and values do continue to be predictive of STEM career pathway persistence up to 4 years after graduation.
\end{abstract}

\section{INTRODUCTION}

The inability to achieve STEM (science, technology, engineering, and mathematics) workforce goals in the United States has long been attributed to the leakage of the academic "pipeline"-particularly for underrepresented minorities (URMs). Specifically, while there have been some gains, national data continue to show that the disparity in STEM degree attainment for URM students-African-American, Hispanic, or Latino/Latina, American Indian/Native American, and Alaskan Native studentsincreases at each degree level, compared with white and Asian students (National Center for Education Statistics, 2005; DePass and Chubin, 2009; Estrada et al., 2016). At each stage of the academic process, URM students are consistently less likely to persist in STEM degree programs than white or Asian students. The end result is underrepresentation of members of these groups in STEM research careers. This educational disparity has attracted considerable commentary, including the application of theoretical models to understand and address this issue (e.g., Bandura, 1997; Gándara and Maxwell-Jolly, 1999; Lewis, 2003; President's Council of Advisors on Science and Technology, 2012; National Academies of Sciences, Engineering, and Medicine, 2016). This paper takes one such model, which emerged from the field of social psychology, the tripartite integration model of social influence (TIMSI; Estrada et al., 2011), and assesses the ability of the model to predict persistence using longitudinal data from a
Jose Herrera, Monitoring Editor Submitted April 17, 2017; Revised October 17, 2017; Accepted October 19, 2017

CBE Life Sci Educ March 1, 2018 17:ar9 DOI:10.1187/cbe.17-04-0066

*Address correspondence to: Mica Estrada (mica estrada(aucsf.edu).

(c) 2018 M. Estrada et al. CBE-Life Sciences Education (๑) 2018 The American Society for Cell Biology. This article is distributed by The American Society for Cell Biology under license from the author(s). It is available to the public under an Attribution-Noncommercial-Share Alike 3.0 Unported Creative Commons License (http://creativecommons.org/licenses/ by-nc-sa/3.0)

"ASCB ${ }^{\oplus "}$ and "The American Society for Cell Biology ${ }^{\circledR "}$ are registered trademarks of The American Society for Cell Biology. 
national panel of URM students. In addition, this paper examines how research and mentorship experiences contribute toward the development of the TIMSI components-efficacy, identity, and values - which have been shown to predict persistence in intention to pursue a STEM career following graduation.

\section{The Scientific Community as an Agent of Social Influence}

Training new scientists can be described as a process in which students experience social influence from peers, educators, and mentors. As Kelman and Hamilton (1989) describe it, social influence occurs when "a person changes his or her behavior as a result of induction by some other person or group-the influencing agent" (p. 78). Social influence research has traditionally focused on the effect of the social context upon the individual and perceptions of the sources of social influence, and differs from socialization models that focus heavily upon individual difference measures. Social psychologists have shown that social influence is ubiquitous-occurring frequently and in a wide array of situations (Cialdini and Trost, 1998; Chartrand and Bargh, 1999; Schultz et al., 2007; Nolan et al., 2011). Previous research on URM integration into academic communities suggest that even influencing agents' subtle cues can impact interest and persistence. For example, influencing agents can be representatives from the academic community (such as instructors or fellow students), as well as contextual variables (such as posters on a wall or program information pamphlets), which have been shown to impact students' sense of belonging, experiences of stereotype threat, and their intentions to participate in academic community activities (Bandura, 1997; Gándara and Maxwell-Jolly, 1999; Lewis, 2003; Murphy et al., 2007). The student is thus influenced intentionally or unintentionally in the academic environment. Viewing URM persistence in STEM through the lens of social influences leads to different and unanswered questions to potentially expand the research literature on this topic.

\section{Social Influence Literature}

In their review of the social influence literature, Cialdini and Goldstein (2004) focused on specific influence tactics (e.g., the foot-in-the door or door-in-the-face techniques) and emphasized the circumstances under which the tactics do or do not work. While relevant to many contexts, this sort of research is not particularly informative in explaining how complex social influence experiences occur, such as how the scientific community influences a URM student to pursue a scientific research career. First, the influence of academic degree programs seldom rests on a onetime interaction but on ongoing situations in which many incidents of influence are likely to occur. Second, if the student is indeed influenced, it is quite likely that several goal motivators will be activated-including the goals of accuracy, affiliation, and maintaining a positive self-concept, as Cialdini and Goldstein describe. Finally, evidence of social influence occurring is likely to result in a broad spectrum of behavioral changes, not just a single behavioral outcome. While it is conceivable that a onetime interaction could influence a URM student career choice, particularly a significant negative interaction, URM students who leave or complete degrees are equally, if not more likely to have a range of social influence experiences during their student tenure, including interactions with faculty, staff, other students, and course content. To capture multiple experiences of the social influence process, we draw on an early model of social influence.

\section{TIMSI and Complex Social Influence Context}

Herbert Kelman proposed a model of social influence more than 50 years ago that showed how a person's orientation toward a social system predicted the conditions under which a person would conform with the demands of the influencing agent (Kelman, 1958, 1961). Kelman concluded that there were three processes of social influence-compliance, identification, and internalization-which unique antecedent and consequent conditions define. Experimental tests of the theory were conducted to understand a specific incident of influence, much as the recent research on social influence has done. However, several years later, Kelman (1963) expanded upon his initial theory to take into account that social influence often occurs in a more complex social context. In fact, he described social influence as a linkage between the individual and a complex social system (Kelman, 1974). According to Kelman (2006), most situations of influence can be described as falling into one of two categories. The first comprises situations of socialization, in which individuals in a developmental sense are prepared for roles within a society, group, or organization. The second, situations of resocialization, occurs when a situation is "designed to move individuals ... from old to new roles with their accompanying beliefs and values" (Kelman, 2006, p. 8). This may occur in situations of psychotherapy, conversions of various sorts, and acculturation. When a student decides to become a part of a STEM academic community, this latter type, resocialization, potentially describes minority students' journey through academic pathways.

According to Kelman (1958, 2006), each process-compliance, identification, and internalization-describes a unique way in which an individual is oriented to a social system. Compliance occurs when an individual adheres to the rules or norms of the system. With compliance, the person ceases to pursue the behaviors the social system desires if the rewards and approval cease (and/or penalties and disapproval increase significantly). This is referred to as a rule orientation. Estrada et al. (2011) measured this orientation as efficacy, because a student who is rewarded for success in academia will feel able to conduct the behaviors the community requests. Identification occurs when an individual's identity is incorporated into his or her activities within that social system. In this case, the social system defines an aspect of the self and belonging. This is a role or identity orientation. Finally, internalization "reflects an orientation to system values that the individual personally shares" (Kelman, 2006, p. 11), which Kelman refers to as a value orientation. In the TIMSI framework, an individual connects to the social system through adopting the rules, roles, and/or values of the social system. The social influence process varies depending on the person's orientation to the social system.

\section{Rules, Roles, and Values}

Kelman's research (2006) shows that there are three levels of influence that are marked by shifts in the target's internal orientation to the influencing agent, yet regardless of orientation, the same behavior may be exhibited. Given the same context, different orientations may lead to different levels of persistence in 
conforming to community normative behavior (Estrada et al., 2011). For example, if a student is studying science because he or she feels consistently rewarded by good grades and accolades from instructors (i.e., they acquire efficacy), this student may not persist if he or she encounters difficult classes and less academic success. In contrast, students who believe and value that science is integral to making meaningful contributions to society may persist even when courses become difficult. Early research shows that these three orientations measured in the final year of undergraduate education do predict intention to pursue a science career and applications to graduate school. The hypothesis, while logical, has yet to be tested in a longerterm study that assesses career choices up to 4 years after baccalaureate-degree attainment.

Rule Orientation: Scientific Efficacy. Previous research has shown that rule orientation is strongest when students believe that they can perform science-related tasks and skills (Estrada et al., 2011). Yet students feeling they can do the work of a scientist does not automatically mean students identify as scientists or feel they belong to the community of scientists; nor does it tell us whether they find the skills they have acquired valuable. When students exhibit a rule orientation toward the scientific community, they simply are confirming that they had the opportunity to learn, that they complied with learning the required skills of the scientists, and that they assess themselves as capable of doing scientific work. Previous research has shown that URMs having science efficacy is positively related to continuing to pursue a scientific career (Lent, 2007; Chemers et al., 2011) as well as academic achievement (Brown et al., 1989; Hackett et al., 1992). Previous research also has indicated that while efficacy may be a necessary component for integration, it is not the most predictive of persistence when identity and values are also part of the model (Estrada et al. 2011).

Role Orientation: Scientific Identity. Previous research has shown that URM students who identify as scientists (i.e., feel they belong in the community of scientists, affiliates, and perceives science as an important aspect of their identity) are more likely to behave in a manner consistent with the expectations of that role and to pursue a scientific career (Chang et al., 2011; Chemers et al., 2011). There is some evidence that minority students do not experience belonging (Hausmann et al., 2007) and assume academic identity at the same rate as do nonminority students (Hurtado et al., 2009). Stereotype threat research has shown that when there are "signals" or context contingencies that communicate to minority students that they do not belong in the scientific community, students' performances decline, while cognitive vigilance increases (Steele, 1997; Ambady et al., 2001; Murphy et al., 2007). Academic work on critical race theory contends that issues of racism and power permeate the educational context, impacting a plethora of psychosocial and educational outcomes (Delgado and Stefancic, 2012; Leonardo, 2012). Previous research has also shown that, when a science student assumes the identity of a scientist, he or she is more likely to follow the norms of that role and pursue a career in the sciences (Estrada et al., 2011). We hypothesize that role orientation builds upon rule orientation and indicates a deeper level of integration, resulting in greater long-term influence on career choice.
Value Orientation: Internalization of the Values of the Scientific Community. In the context of the scientific community, people exhibit an internalized social influence process when their authentic valuing of the objectives of the scientific community is the primary motivation for their desire to pursue a scientific career. Kelman describes values as specific shared guiding principles held by group members (2006, p. 521). His approach differs from Schwartz's (1999) work, which focuses primarily on 10 cross-cultural value constructs. Kelman's conception of values also differs slightly from Eccles and colleagues' research on subjective task value, which focuses more upon the value of specific tasks and assesses the intrinsic value of a task (Eccles and Wigfield, 2002; Durik et al., 2006). Estrada et al. (2011) developed a measure of values based on Schwartz' portrait value scale, which asks people to rate how much a person is or is not like them who endorses a described value (Schwartz et al., 2001). With this measure, regardless of level of enjoyment or usefulness, when a person rates social group values as important to him- or herself, this is evidence of internalization of that value. The research showed that this measure of scientific values predicted students' integration into the scientific community, even when science efficacy and identity were a part of the model (Estrada et al., 2011).

Time. Previous research on integration, measured as science efficacy, identity, and values predicting persistence in STEM, has typically measured outcomes within a year of baccalaureate-degree attainment. The extent to which undergraduate integration into a professional community results in longer-term STEM career persistence is less well studied.

Program Components That Potentially Increase Integration The TIMSI model offers a useful framework within which to understand how various undergraduate experiences contribute toward the resocialization of URM science students into STEM disciplines. A variety of intervention programs designed to encourage URM persistence in the sciences exist that offer opportunity, support, and training experiences. For university students, these programs are administered through local and national science training programs (STPs). Many of these STPs provide research experience and mentorship for students. While the effectiveness of these programs has attracted national scrutiny in recent years, there is emerging evidence that these programs make a difference (National Research Council, 2005; Schultz et al., 2011). What is less clear is which program components contribute toward persistence.

Research Experience. Across a range of age groups, program designs, intensity, and duration, findings show that undergraduate research experience (in the context of co-curricular programs or within the classroom) are integral to the development and sustaining of interests in STEM careers among students. For example, Laursen et al. (2010) concluded that research experience positively influences career choice, placement, decision making, and preparation. The evaluation studies they cite in their review of the literature on research experience rely heavily on descriptive accounts of research experiences from programs with small sample sizes. In recent years, a variety of larger research programs have started to show reliable impacts of research experience relating to degree 
completion and persistence in interest in STEM careers using quasi-experimental designs and statistical modeling (Barlow and Villarejo, 2004; Villarejo and Barlow, 2007; Jones et al., 2010; Chemers et al., 2011; Schultz et al., 2011). Their analyses suggested that research participation directly contributed to persistence.

In summary, the evidence suggests that co-curricular programs with a research experience component are more likely to contribute toward developing and sustaining interest in STEM fields (Estrada, 2014). The majority of studies cited here, however, have focused on persistence in biology or biomedical fields. Very little prospective research has examined why research experience relates to URM persistence in STEM fields or how it predicts prospectively career choices up to 4 years after baccalaureate-degree attainment.

Mentorship. Mentoring is the second core component of many intervention programs. Mentorship refers to a relationship between a seasoned, experienced person-a mentor-and a less experienced person-the protégé (Rhodes, 2005). Within the context of this relationship, there is the expectation that the protégé will develop professionally under the guidance of the mentor (Eby et al., 2007), receive career assistance and support (Jacobi, 1991), and serve as a significant institutional agent in promoting student engagement (Chen et al., 2008). Some scholars have made the assumption that mentorship is beneficial, resulting in academic achievement, productivity in scholarship, academic persistence, and even psychological health (Tenenbaum et al., 2001; Johnson et al., 2007). At the same time, other scholars have provided strong critiques of the methodological limitations of this field of study (Crisp and Cruz, 2009; National Academies of Sciences, Engineering, and Medicine, 2017). Meta-analyses of mentor-protégé studies indicate that three factors emerge as important to protégé experiencing positive outcomes (Eby et al., 2013). First, mentors can provide instrumental support, providing resources and opportunity to the protégé to engage in goal attainment (Kram, 1985), which can include "the specific mentor behaviors of providing task-related assistance, sponsorship, exposure and visibility, and coaching" (Eby et al., 2013, p. 3). Second, psychosocial support occurs when a mentor enhances "an individual's sense of competence, identity, and effectiveness in a professional role" (Kram, 1985, p. 32). This may also include facilitating emotional and personal development (Flaxman et al., 1988; Nakkula and Harris, 2013). A third, relationship quality (sometimes referred to as "relationship satisfaction") is an affective assessment of liking, which may include feelings of trust, empathy, respect, and connectedness (Ragins, 2010). Most of the empirical research showing mentorship is important to positive outcomes emerges from studies of youth mentorship and the business world (meta-analyses by Allen et al., 2004), with the outcome of these studies typically being academic and career advancement. However, Eby et al.'s (2013) meta-analysis of mentorship research shows that there is robust evidence for instrumental and psychosocial support contributing to relationship quality in a self-enforcing cycle. And the combination of these mentorship qualities is positively related to performance, motivation, career outcomes, and health for protégés. Examining how mentorship impacts URM student development of science efficacy, identity, and values across time will extend current research in this area that indicates that the quality of mentorship is important in URM mentor-protégé experiences (Thiry and Laursen, 2011; Byars-Winston et al., 2015).

\section{Summary}

In this paper, we will use structural equation modeling (SEM) to look at how URM students integrate into the scientific community across time. Specifically, we test a model that seeks to answer two research questions: 1) Does research experience and mentorship contribute toward integrating undergraduates into STEM fields? 2) Do URM undergraduate students' science self-efficacy, identity, and values (measures of student integration into the scientific community) positively relate to persistence in STEM career pathways up to 4 years later? On the basis of previous research, we hypothesized that research experience and quality mentorship during undergraduate education will positively predict science self-efficacy, scientific identity, and the valuing of the objectives of the scientific community. Further, we hypothesized, extrapolating from previous findings, that each of the above variables will be positively correlated with choosing a STEM career and negatively correlated with choosing a non-STEM career 4 years after graduation. Moreover, on the basis of previous research, we hypothesized that science identity and valuing the objectives of science as an undergraduate will be unique positive predictors of choosing a STEM career. To answer these research questions and test the stated hypotheses, we analyzed data from a longitudinal prospective study of undergraduate URM science students. These data cover a 6-year span of time in which students persisted in STEM, left STEM, or pursued a medical/clinical career. More specifically, and as shown in our conceptual model (Figure 1), we simultaneously modeled the influence of mentor quality and research experiences on science efficacy, identity, and values (research question 1) and influence of science efficacy, identity, and values on distal career outcomes (research question 2), controlling for relevant background, demographic, and institutional characteristics.

\section{METHODS}

The data for this study were drawn from a national, longitudinal panel of URM science students that began in 2005, and we use data from the students' junior and senior years of undergraduate study and STEM persistence 6 years later.

\section{Participants and Procedure}

A longitudinal panel of 1420 minority science students (undergraduate and graduate) was recruited from 50 universities across the United States. The purpose of the study was to investigate the long-term impact of participation in URM-focused biomedical/science training programs (i.e., National Institutes of Health [NIH]-funded Research Initiative for Scientific Enhancement [RISE] program and similar programs). Therefore, in 2005, we recruited URM biomedical/science majors enrolled in RISE or similar programs and matched URMs not enrolled in a science training program. We recruited students from the 25 college campuses running RISE programs and from 25 matched college campuses that did not have a RISE program. Matched campuses were identified based on similar demographic and geographic locations. 


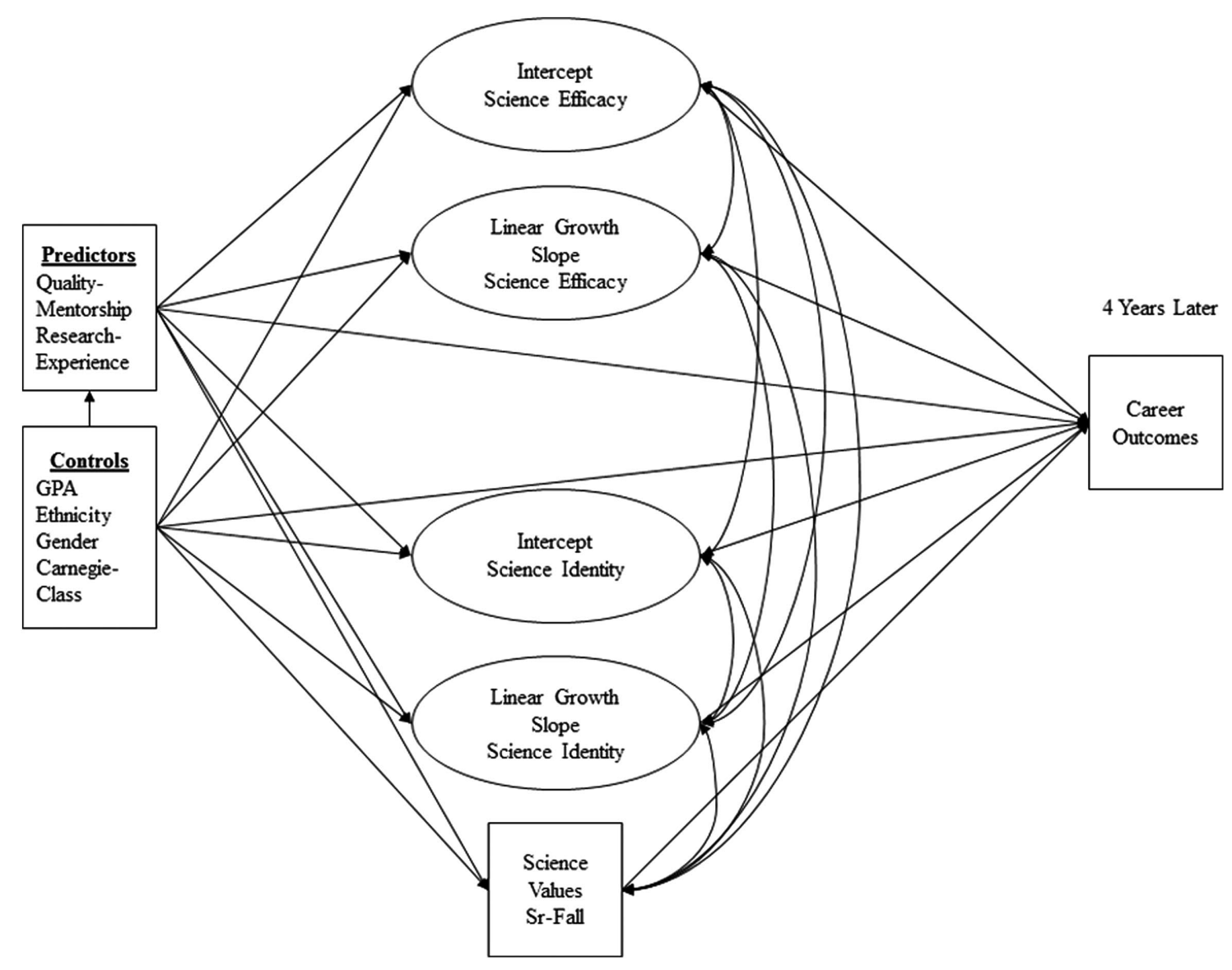

FIGURE 1. Conceptual model showing expected direct and indirect effects of quality of mentorship and research experiences on TIMSI variables and career outcomes, controlling for individual and institutional characteristics.

Consistent with the mission of the RISE program, participants were considered "minority" if 1) they were a member of an ethnic or disability group that was deemed underrepresented in U.S. biomedical/science graduate degree programs and faculty positions in 2005 , or 2 ) they were a member of any other group determined to be underrepresented in biomedical fields as determined by campus-level institutional policies (which varied across RISE campuses). Because RISE and similar programs primarily recruit during the junior and senior years, our targeted sampling approach also focused primarily on URMs in their junior and senior years, who were recruited through email and announcements made in upper-division gateway science courses (e.g., organic chemistry) on each campus. All potential participants completed a brief baseline recruitment survey in the Fall of 2005 consisting of background information (e.g., parental education), demographics (e.g., race/ethnicity), academic characteristics (e.g., major, year in school), and intention to pursue a scientific career. Students received small incentive for their participation in the recruitment study (\$5). Students with complete information and self-reporting a strong intention to pursue a scientific research career were recruited into the larger study.

Starting in the Spring of 2006, participants responded to biannual (Fall and Spring) online surveys concerning their edu- cational status (e.g., college senior majoring in chemistry; enrolled in $\mathrm{PhD}$ program in cell biology), educational and professional aspirations and attainment (e.g., intention to pursue a scientific research career), engagement in scientific activities (e.g., participation in lab research), and status on a number of theoretically relevant individual differences (e.g., scientific self-efficacy); participants received a small incentive for their participation in the study ( $\$ 25$ per survey).

The analytic sample reported in this paper consists of students who completed the surveys in their junior and senior years $(78 \%$ of the full panel, i.e., removed graduate students, $n=184$ ). Of this subsample, the small number of participants who did not provide any usable data in their junior or senior years $(n=221)$ were not included in the analysis. The final analytic sample $(N=1015)$ consisted of students who responded to the survey at least once during their junior or senior years. When recruited into the panel, the participants were primarily in their early twenties $(\mathrm{M}=21.49, \mathrm{SD}=3.58)$ and female (72\%), and the sample consisted of African-American students (47.0\%), Hispanic/Latino/Latina students (40.3\%), and a smaller proportion of students (12.7\%) from other racial backgrounds (i.e., Asian, Hawaiian/Pacific Islander, Native American/Alaskan Native, white-non-Hispanic [e.g., of Middle Eastern descent]). 


\section{Measures}

Scientific Self-Efficacy: Indicator of Rule Orientation. A sixitem self-efficacy scale used in prior research (Estrada et al., 2011), asked participants to assess their ability to function as a scientist in a variety of tasks (e.g., "generate a research question to answer"). Each statement was assessed on a scale of 1 (not at all confident) to 5 (absolutely confident). This scale was administered each semester (Fall and Spring) from junior through senior years.

Scientific Identity: Indicator of Role Orientation. A five-item scientific identity scale used in prior research (Estrada et al., 2011) asked participants to assess to what extent a statement was true of them (e.g., "I have a strong sense of belonging to the community of scientists"). The participants assessed each statement on a scale of 1 (strongly disagree) to 5 (strongly agree). This scale was administered the Fall and Spring semesters of junior year and the Fall semester of senior year.

Science Community Value Scale: Indicator of Value Orientation. A four-item values scale used in prior research (Estrada et al., 2011) asked participants to read descriptions of a person (e.g., "a person who feels discovering something new in the sciences is thrilling") and to rate "how much the person in the description is like you." The participants responded on a scale from 1 (not like me at all) to 6 (very much like me), which is a classic response option for studying values (Schwartz et al., 2001). This scale was introduced into the study later than the efficacy and identity scales. Thus, the scale was only administered in the Fall semester of senior year.

Average Research Experience in Junior and Senior Years. Students were asked whether they had "worked in a laboratory at their current university," "worked in a laboratory at another university," or had "worked on research at another location" over the previous 6 months. Responses were dummy coded into a research experience variable $(0=$ no research experiences; $1=$ research experience). Student responses were averaged over the Spring of junior year and Fall of senior year and recoded into two contrast-coded binary variables indicating one semester of research ( 1 = one semester; -1 otherwise) and two semesters of research ( 1 = two semesters; -1 otherwise).

Average Mentor Relationship Quality in Junior and Senior Years. Students with faculty mentors were asked to broadly assess the quality of their mentoring relationships using a nineitem scale of mentor support adapted from Dreher and Ash (1990; see the Supplemental Material for items). Participants reported the extent to which their mentors provided psychosocial support, instrumental support, and networking support on a scale from 1 (not at all) to 5 (to a very large extent). Participants without a mentor did not complete these scales, and their data were coded as missing values. These scales were administered in the Spring of junior year and Fall of senior year. The Spring and Fall mentor-quality scores were averaged, and a single index of mentor quality in junior and senior years was included in our analysis.

Career Choice. Beginning in the Fall of 2011, 4 years after baccalaureate attainment in the sample (on average), partici- pants were asked to report on their current occupations. Responses were coded into three mutually exclusive categories: STEM career, which included the pursuit (e.g., graduate students in STEM-focused fields) and attainment of STEM-related careers (e.g., "analytic chemist," "assistant professor of biology," "sixth-grade earth science teacher"; $n=302$ ); medical/clinical career (e.g., "medical doctor-pediatric resident," "occupational therapist," "bilingual school psychologist"; $n=197$ ); other profession (e.g., "police officer," "special education teacher," "food service," "homemaker"; $n=195)$. Two graduate student raters (kappa $=0.99)$ coded participant responses $(N=694)$, and disagreements were resolved by M.E. The career choice variable was dummy coded into three variables: STEM career $(0=$ nonSTEM career; 1 = STEM career $)$; medical career $(0=$ nonmedical career; $1=$ medical career $)$; other career $(0=$ STEM or medical career; 1 = other career).

Controls. Demographic information, such as gender and ethnicity, and current college cumulative grade point average (GPA) were self-reported baseline. Gender was contrast coded into a single variable with females as the reference group $(-1=$ female; 1 = male). Ethnicity was recoded into five contrast-coded variables with African Americans as the reference group. College/university Carnegie classification was recoded into seven contrast-coded variables with baccalaureate colleges (diverse fields) as the reference group.

Auxiliary Variables. Auxiliary variables were included in our analysis. The list of variables included: year in school at the time of recruitment, science training program status, undergraduate institution, field of study, year of recruitment, transfer status, and intention to pursue a scientific research career, living situation at baseline (e.g., living with parents), parental highest level of education, English as a first language status, and age.

Data Structure and Treatment of Missing Data. The data were collected in linear time (e.g., Spring 2006, Fall 2006, Spring 2007) but were restructured based on year in school (e.g., junior-Fall semester, junior-Spring semester, senior-Fall semester, senior-Spring semester) for the analysis. Given the sampling design described earlier, each variable in our data set exhibited varying degrees of missing data (Supplemental Table 1 shows missing data information on each variable). For example, a relatively small proportion of our sample was recruited into the study in time to complete the junior year Fall semester survey (i.e., most completed the baseline survey in the Fall semester of junior or senior years and started the full survey in the Spring of junior or senior years). In addition, individuals exhibited a variety of idiosyncratic patterns of missing data.

To determine whether the patterns of missing data met the strict assumption of being missing completely at random (MCAR) required for unbiased parameter estimates under ordinary least-squares (OLS) regression, we conducted Little's MCAR test (Little, 1988; Schafer and Graham, 2002). Results indicated that the data were not missing completely at random, $\chi^{2}(1009)=1180.42, p<0.001$. To satisfy the less-strict assumption of missing at random required in an SEM framework, we used data collected in the baseline recruitment to identify auxiliary variables associated with missing data (Collins et al., 2001; 
Enders, 2010). We identified 14 variables that were correlated with indicators of missing data for each variable in our missing data model. Logistic regression models predicting indicators of missing data for each variable (dummy coded: $0=$ nonmissing; $1=$ missing) showed that, as a set, the auxiliary variables significantly predicted missing (Nagelkerke $R^{2} \mathrm{M}=0.63, \mathrm{SD}=0.22$ ). The auxiliary variables included the following:

- Academic characteristics and motivation: year in school at the time of recruitment (e.g., students recruited in senior year had missing data in junior year), science training program status (e.g., RISE, non-RISE comparison group), undergraduate institution, baseline cumulative college GPA, field of study (e.g., biological sciences), year of recruitment (2005, 2006, or 2007), transfer status, and intention to pursue a scientific research career.

- Background characteristics and demographics: living situation at baseline (e.g., living with parents), parental highest level of education, ethnicity, gender, English as a first language status, and age.

All auxiliary variables were entered into the substantive analysis models to reduce potential bias (Collins et al., 2001).

Model Fit. Model fit was assessed with a variety of fit indices. In addition to reporting the model chi-square $\left(\chi^{2}\right)$ and degrees of freedom, we the report root-mean-square error of approximation (RMSEA) and the comparative fit index (CFI). Consistent with current standards, we evaluated model fit indices relative to recommended cutoff values (Hu and Bentler, 1999). RMSEA values at or below 0.05 (or RMSEA 90\% confidence intervals [CIs] that included 0.05) and CFI values at or above 0.95 indicated good data-model fit. Assessment of the statistical significance of individual parameter estimates (e.g., regression slopes) followed assurance that the model fit was acceptable (Thompson, 2004). We evaluated the statistical significance of parameter estimates at a typical 0.05 alpha level, because we focused on a small set of hypothesis tests rather than employing exploratory post hoc model modifications, which are known to inflate familywise error rate and type I error controls (Green and Babyak, 1997; Hancock, 1999).

Modeling Approach. Given the nature of the distal career outcomes (i.e., binary variables) and missing data, all models were estimated using weighted least-squares Mplus, version 7.11 (Muthén and Muthén, 1998-2009). Auxiliary variables, as described above, were incorporated into the models to correct for potential bias due to data missing at random (see the Supplemental Material section on preliminary growth model analytic description for full details of the iteration of the model and analytic response to nested structure).

\section{RESULTS}

\section{Predicting Development of TIMSI from Research and Mentoring}

We addressed our first research question (i.e., the degree to which mentoring and research contribute to integration into the scientific community) by estimating the model depicted in Figure 1, which assessed the influence of quality mentorship and research experiences on levels and growth in science efficacy, science identity, and science community values, over and above various control variables (i.e., demographic characteristics [i.e., gender and ethnicity], academic achievement [baseline GPA], and institutional characteristics). In addition, the parallel models addressed our second research question (i.e., the degree to which integration into the scientific community influences career choice) by assessing the impact of levels of and growth in science efficacy, identity, and community values on the distal outcomes of choosing a STEM, medical, or other career, over and above the quality of mentorship, research experiences, and the control variables. When estimating the model that used STEM career as the distal outcome, the analysis revealed that the science identity growth slope's near-zero variance caused problems for model convergence. Therefore, we constrained the variance of the science identity growth slope to zero for this and all following analyses. Model fit was acceptable $\left(\chi^{2}[d f=123]=188.80, p<0.001\right.$; RMSEA $=0.02,90 \% \mathrm{CI}$ $[0.01,0.03]$; CFI $=0.94)$, and the model constraint on science identity growth slope variance did not worsen model fit $\left(\Delta \chi^{2}[d f=3]=3.30, p=0.35\right)$.

An inspection of the parameter estimates indicated that, as expected, the quality of mentorship and research experiences had small positive effects on the level (i.e., intercept) of science efficacy, but neither influenced the rate of science efficacy growth (see Figure 2 for simplified model with standardized parameter estimates and Table 1 for complete details with unstandardized parameter estimates). For example, the analysis indicated that a 1 SD increase in quality of mentorship was associated with a 0.31 SD increase in the science efficacy intercept (i.e., level of science efficacy in Fall semester of senior year), controlling for other factors in the model. Furthermore, students with two semesters of research experiences had science efficacy intercept scores 0.22 SD higher than students with no research experience. Similarly, the quality of mentorship and research experiences had small positive effects on the intercept of science identity and science community values. As a set, the predictors and control variables explained a moderate proportion of variance in science efficacy (intercept and slope), science identity (intercept), and science community values (see caption to Figure 2).

\section{Predicting Career Choice from TIMSI Development}

To address our second research question, we inspected the portion of the model predicting STEM career choice. Partially consistent with our expectations, the science identity intercept (i.e., level of science identity in Fall of senior year) significantly and positively predicted STEM career choice. This finding indicates that higher levels of science identity increased the probability of choosing a STEM career 4 years, on average, postgraduation (Figure 2 and Table 1).

Next, a second model was fitted to the data with medical career as the distal outcome. As before, the model exhibited acceptable fit to the data $\left(\chi^{2}[d f=123]=190.39, p<0.001\right.$; RMSEA $=0.02,90 \%$ CI $[0.01,0.03]$; CFI $=0.93)$. However, only baseline GPA predicted choosing a medical/clinical career (Table 1).

A third model was fitted to the data with other career as the distal outcome. As before, the model exhibited acceptable fit to the data $\left(\chi^{2}[d f=123]=186.81, p<0.001\right.$; RMSEA $=0.02$, $90 \%$ CI $[0.01,0.03]$; CFI $=0.94)$. An inspection of the parameter estimates showed that science identity intercept significantly 


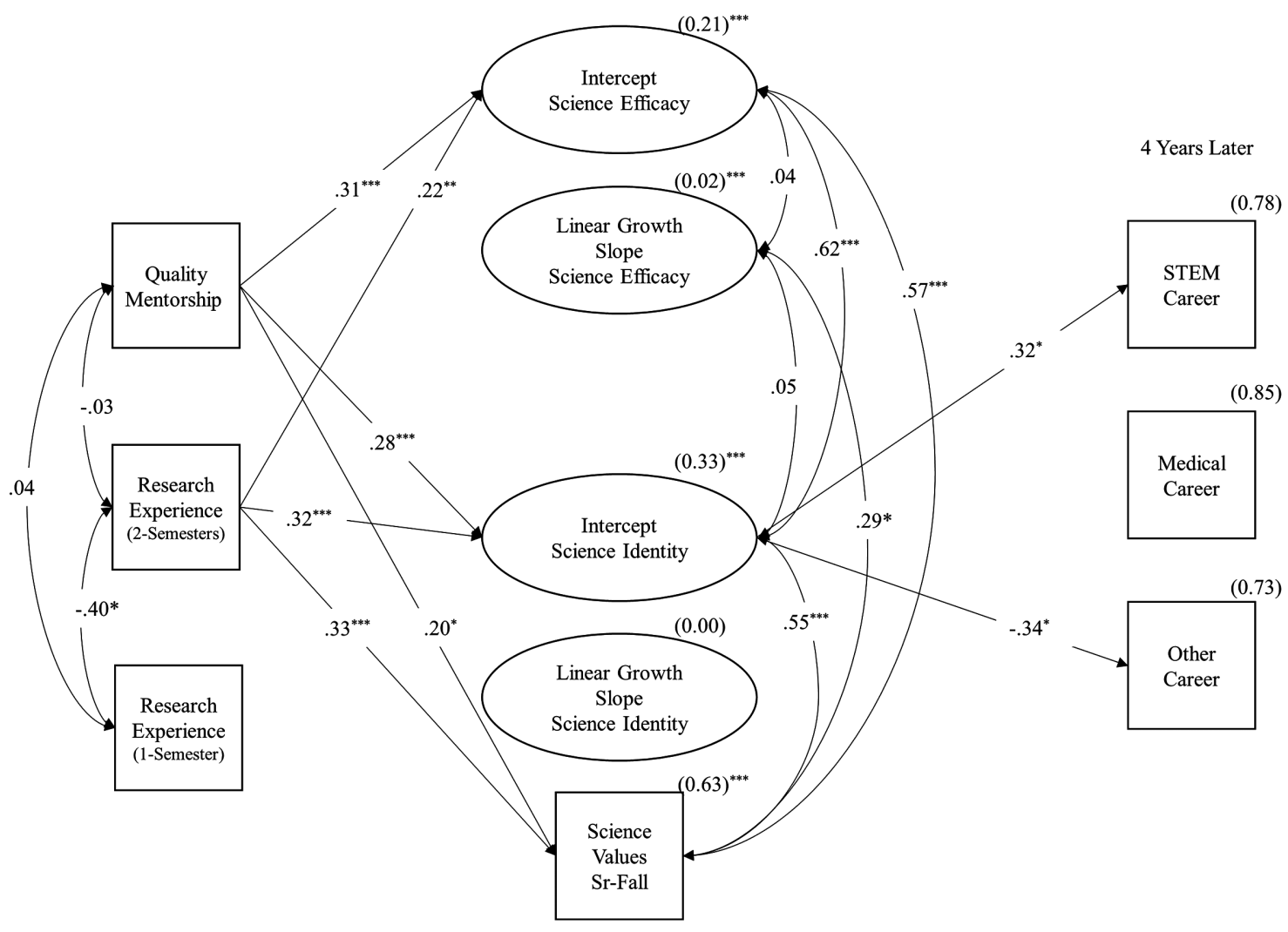

FIGURE 2. Simplified model showing significant direct and indirect effects of quality of mentorship and research experiences on TIMSI variables and career outcomes. Values on paths/arrows represent standardized structural coefficients; values on curved double-headed lines represent correlation coefficients; values inside parentheses represent residual variance. Proportion of variance explained $\left(R^{2}\right)$ by the complete set of predictors was calculated for all TIMSI and career outcome variables and the values were as follows: $R^{2}$

$0.17 ; R^{2}$ $=0.14 ; R^{2}$ ${ }^{*}, p \leq 0.05 ;{ }^{* *}, p \leq 0.01 ;{ }^{* * *}, p \leq 0.001$.

and negatively predicted other career. This finding indicates that higher levels of science identity decreased the probability of choosing a career outside STEM or medicine.

\section{Exploratory Mediation Model}

As a final step, we explored potential indirect effects of mentoring quality and research experiences on STEM and other career outcomes using a bootstrapping procedure. Specifically, a percentile bootstrap (with 5000 repetitions) was used to estimate the $95 \%$ CIs around the indirect effects of quality mentorship and research experiences on STEM or other career choice through the science identity intercept (Shrout and Bolger, 2002; MacKinnon et al. 2004, 2007, MacKinnon, 2008). The results indicated that quality mentorship and two semesters of research experiences exhibited significant positive indirect effects on STEM career choice through science identity (indirect effect $_{\text {Mentor quality }} \rightarrow_{\text {Science identity (Intercept) }} \rightarrow_{\text {STEM career }}=0.14,95 \%$ CI [0.01, $0.35]$; indirect effect Research experience $\rightarrow_{\text {Science identity (Intercept) }} \rightarrow_{\text {STEM career }}=$ $0.12,95 \%$ CI $[0.01,0.28])$. However, quality mentorship and two semesters of research experiences did not exhibit significant indirect effects on other career choice through science identity (indirect effect ${ }_{\text {Mentor quality }} \rightarrow_{\text {Science identity (Intercept) }} \rightarrow_{\text {Other career }}=$ $-0.10,95 \%$ CI $[-0.31,0.01]$; indirect effect ${ }_{\text {Research experience }} \rightarrow$ Science identity (Intercept) $\rightarrow_{\text {Other career }}=-0.11,95 \%$ CI $\left.[-0.28,0.02]\right)$.
In summary, the results were partially consistent with our expectations and are summarized in Table 2. Concerning the first research question, we found that quality mentorship and two semesters of research experiences in a student's junior and senior years did positively predict their scientific self-efficacy, identity, and scientific values. But we also found that only quality mentorship positively predicted linear growth in science efficacy over junior and senior years. Concerning the second research question, we found that scientific identity predicted career choices in a manner consistent with expectations (i.e., positive predictor of STEM careers and negative predictor of other careers).

\section{DISCUSSION}

The overarching purpose of this paper was to first explore, via a social influence framework, how undergraduate research and mentorship experiences contribute toward the integration of students into their professional communities and under what circumstances undergraduate integration predicts longer-term STEM career persistence. Specifically, we sought to answer two research questions: 1) Does research experience and mentorship contribute toward integrating undergraduates into STEM fields? 2) Do URM undergraduate students' science self-efficacy, identity, and values (measures of student integration into the 


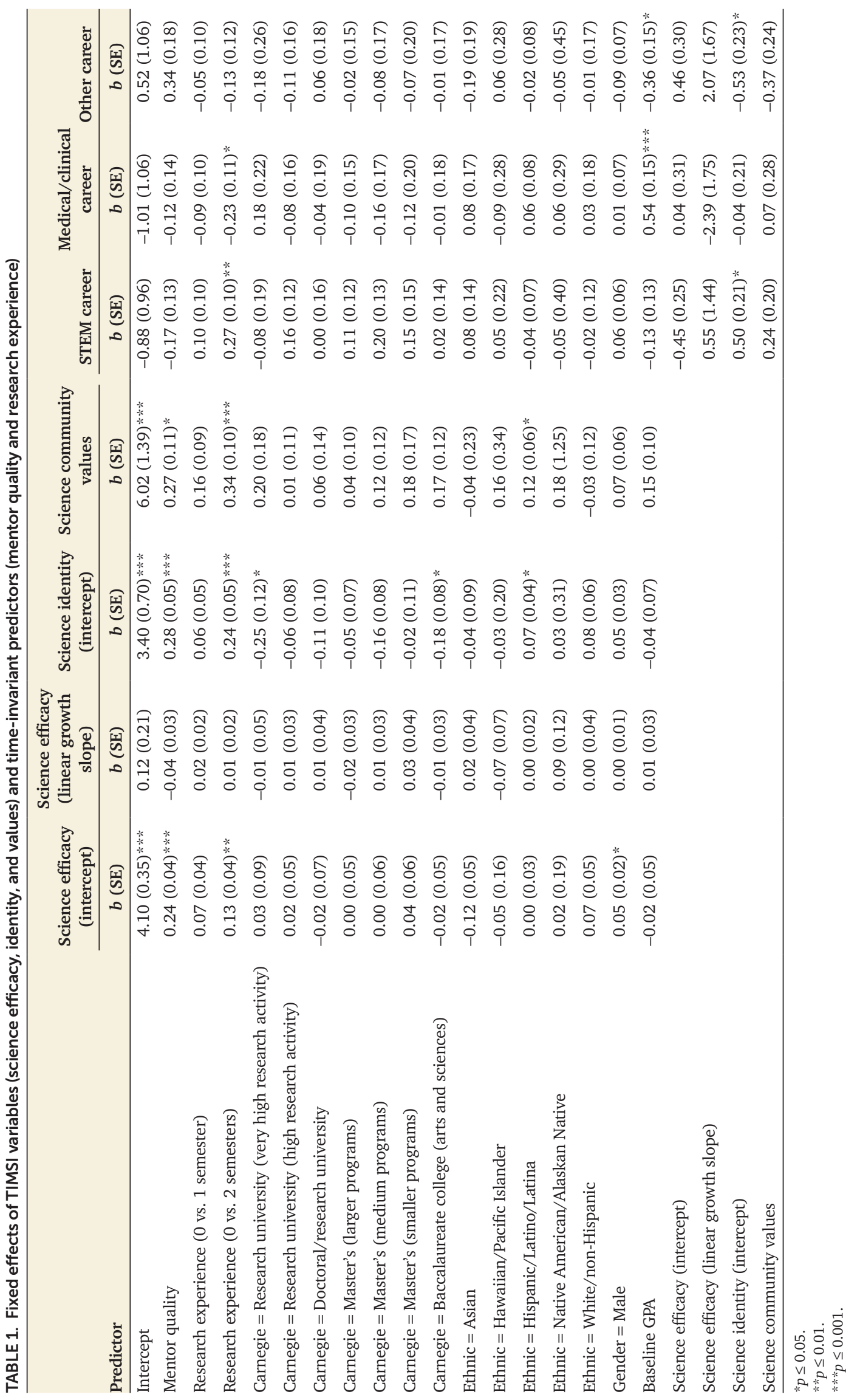


TABLE 2. Summary of research questions, hypotheses, and results

\begin{tabular}{lr}
\hline Research question & Hypothesized outcome \\
\hline How does research experience and mentorship & Research experience during undergraduate \\
contribute toward integrating undergradu- & education will positively predict science \\
ates into STEM fields? & self-efficacy, scientific identity, and the \\
& valuing of the objectives of the scientific \\
& community.
\end{tabular}

Quality mentorship during undergraduate education will positively predict science self-efficacy, scientific identity, and the valuing of the objectives of the scientific community.

Do URM undergraduate students' science self-efficacy, identity, and values (measures of student integration into the scientific community) positively relate to persistence in STEM career pathways up to 4 years later?
Efficacy will positively predict choosing a STEM career and negatively predict choosing a non-STEM career 4 years after graduation.

Science identity will positively predict choosing a STEM career and negatively predict choosing a non-STEM career 4 years after graduation.

Valuing the objectives of science as an undergraduate will positively predict choosing a STEM career and negatively predict choosing a non-STEM career 4 years after graduation.

\section{Result}

This hypothesis was partially confirmed. One semester of research experience did not significantly predict integration variables, while two semesters of research experience did uniquely predict overall science self-efficacy, identity, and values.

This hypothesis was partially confirmed. Quality mentorship uniquely predicted overall science self-efficacy, identity, and values. However, quality mentorship did not predict growth in science efficacy.

This hypothesis was partially confirmed. Efficacy was significantly related to, but did not uniquely predict, STEM career choice or negatively predict other career choice 4 years after graduation.

This hypothesis was confirmed. Science identity related to and uniquely predicted STEM career choice and negatively predicted other career choice 4 years after graduation.

This hypothesis was partially confirmed. Values were significantly related to, but did not uniquely predict, STEM career choice or negatively predict other career choice 4 years after graduation. scientific community) positively relate to persistence in STEM career pathways up to 4 years later? Our results are drawn from a 6-year span of time, in which students persisted in STEM, pursued medical careers, or left for other careers.

\section{STEM Training Attributes and Integration}

Overall, the results show that research and quality mentorship experiences contribute toward integrating undergraduates into STEM fields. On the basis of previous research, we hypothesized that research experiences and quality mentorship (providing psychosocial, instrumental, and networking opportunities) would positively predict the development of science self-efficacy, scientific identity, and the valuing of the objectives of the scientific community (such as scientific discovery or advancing knowledge). The data confirmed this hypothesis. Overall, we did find that quality mentorship and two semesters of research experience that occurred in the junior and senior years of undergraduate education were positively related to student science efficacy, identity, and/or values at that same time period. Neither research nor mentorship experience predicted growth of science efficacy. Overall, however, both research and quality mentorship experiences contributed toward socializing and integrating students in a manner that made them more likely to persist in STEM fields at the time of graduation (Estrada et al., 2011) and were consistent with retrospective studies examining similar variables (Barlow and Villarejo, 2004), including how STEM confidence develops among ethnically diverse students (Litzler et al., 2014). In sum, the hypothesis was confirmed that two semesters of research experiences and quality mentors play a significant role in integrating students into the STEM community.

\section{TIMSI Relationship to Long-Term STEM Career Choice}

The Individual Relationships. Overall, the hypothesis that efficacy, identity, and values would predict persistence in STEM fields 4 years after graduation received only partial support. Specifically, correlational results indicated that scientific identity and valuing the objectives of science positively and significantly related to URM students choosing to pursue a STEMbased career (i.e., STEM major in graduate school or working in a STEM profession) and negatively related to pursuing other (nonmedical or non-STEM) careers (see Supplemental Table 1 for correlation results). Science efficacy showed a weaker relationship to persistence in STEM. Previous research on efficacy had shown that science efficacy contributes toward persistence. However, previous research typically had shorter gaps, such that STEM interest was measured by a student's interest in participating in STEM-related activities (e.g. Lopez et al., 1997; Luzzo et al., 1999; Lent et al., 2001) or in pursuing a STEM-related major (Lent et al., 2005) within a couple of months from when efficacy was measured. Thus, the results of this study add to the efficacy research and suggest that, while efficacy is important and perhaps a necessary predictor of moving toward a STEM career, past experiences of efficacy may not be sufficient for maintaining longer-term persistence.

Unique Predictors of Persistence. We hypothesized, on the basis of previous research, that science identity and valuing the objectives of science would uniquely and positively predict choosing a STEM career, because these variables had previously predicted intention to pursue biomedical careers following graduation. However, the results of our full structural equation 
model showed that only identity was a unique predictor of STEM careers 4 years after graduation and a negative predictor of leaving STEM and medical career pathways. With science identity and values being so strongly related to each other, each variable's unique relationship to STEM persistence is not evident, because they are sharing similar variance. Other research on these constructs does suggest, however, that as students progress in their academic journeys, endorsing the values of the scientific community may become increasingly unique from having a scientific identity when predicting STEM career choice and persistence (Gibbs and Griffin, 2013). These results, however, show that this distinction is not present at the time of graduation. Further research examining growth after graduation is needed to better understand the unique and shared predictive value of these variables.

Finally, we note that none of the social integration significantly predicted pursuit of a medical career. This lack of a significant relationship may reflect that science efficacy, identity, and values, while highly connected to the scientific career community, are not well connected to the medical career community, which has more emphasis on healthcare than scientific discovery. These results suggest that, at this time, a different set of skills, identity, and value emphasis may discriminate those who choose medical professions from those who choose research careers.

\section{Caveats}

There are several caveats that should be noted.

Participants. Our panel did not include ethnic majority students. Thus, these results cannot be generalized to all populations, because these URM students do have unique cultural and developmental experiences that are not the same as those from the "majority" American culture. Future research that examines how both majority and minority students integrate into STEM communities would be useful and informative. However, given the disproportionate number of URMs who leave STEM careers, this particular sample provides important information about how interventions contribute toward persistence in STEM fields.

Interventions. The interventions in this study, research experience and mentorship, were not manipulated or standardized across participants. Our conclusions are drawn based on student self-reports of engagement and student perceptions of quality mentorship. These results do contribute significantly to the literature on these topics, in that they demonstrate the type of short- and longer-term impacts these interventions may have on students. However, additional research in which these interventions can be standardized across students and experimentally tested would provide additional and important results for research in this area. Also, examining whether mentor assessment of the quality of the mentee-protégé relationship is more predictive of long-term impacts than protégé perceptions would be important to assess. The findings from this study suggest that student perceptions of quality mentorship do appear to relate to indices of integration.

STEM, Medical, and Other Careers. We chose to create three career option outcomes that included STEM, medical, and nonscience fields. Given the national interest in increasing persistence of URMs in STEM fields, this trichotomy makes sense. At the same time, we acknowledge that career persistence rates in all STEM fields are not identical. Particularly for women, national persistence trends are much higher in science than the other three fields, with women receiving more than half of bachelor's degrees awarded in the biological sciences and fewer degrees in the computer sciences (18.2\%), engineering (18.4\%), and mathematics and statistics (43.1\%; National Science Foundation, National Center for Science and Engineering Statistics, 2013). However, for students interested in research careers, the split between STEM versus medical career paths occurs often, with a greater number of URMs traditionally opting for medical careers (Council on Graduate Medical Education, 2005). Future research may also productively seek to better understand URM and majority student variations in pursuing particular STEM disciplines and careers.

\section{CONCLUSIONS}

This study provides one of the first prospective, longitudinal studies of how URM students integrate (or not) into professional STEM communities, and how their integration process differs from those who choose to pursue medical or non-STEM careers. The study results show that undergraduate social experiences matters. When students experience quality mentorship and engage in research experiences, they are more likely to experience social integration. The full model further suggests that the current approaches of providing research and quality mentorship experiences to URM students may be contributing significantly to the current URM persistence rates and could possibly play stronger roles in increasing retentions if "scaled up" to reach more students. Further, viewing student persistence through the lens of social influence, new questions can be asked regarding how students shift internally and are impacted by the environment that is socializing them. The findings regarding the strong and unique predictive value of science identity are promising and suggest that higher education institutions that provide authentic experiences of belonging and inclusion, which are components of science identity, may be more likely to increase their URM retention rates.

\section{ACKNOWLEDGMENTS}

The research reported in this paper was supported by a grant from the NIH (R01-GM075316). We gratefully acknowledge Anna Woodcock, Lilibeth Flores, and Maria Aguilar's contributions to this research.

\section{REFERENCES}

Allen, T. D., Eby, L. T., Poteet, M. L., Lentz, E., \& Lima, L. (2004). Career benefits associated with mentoring for proteges: A meta-analysis. Journal of Applied Psychology, 89(1), 127. doi: 10.1037/0021-9010.89.1.127

Ambady, N., Shih, M., Kim, A., \& Pittinsky, T. L. (2001). Stereotype susceptibility in children: Effects of identity activation on quantitative performance. Psychological Science, 12(5), 385-390.

Bandura, A. (1997). Self-efficacy: The exercise of control. New York: Freeman Barlow, A. E., \& Villarejo, M. (2004). Making a difference for minorities: Evaluation of an educational enrichment program. Journal of Research in Science Teaching, 41(9), 861-881.

Brown, S. D., Lent, R. W., \& Larkin, K. C. (1989). Self-efficacy as a moderator of scholastic aptitude-academic performance relationships. Journal of Vocational Behavior, 35, 64-75. 
Byars-Winston, A. M., Branchaw, J., Pfund, C., Leverett, P., \& Newton, J. (2015). Culturally diverse undergraduate researchers' academic outcomes and perceptions of their research mentoring relationships. International Journal of Science Education, 37(15), 2533-2554.

Chang, M. J., Eagan, M. K., Lin, M. H., \& Hurtado, S. (2011). Considering the impact of racial stigmas and science identity: Persistence among biomedical and behavioral science aspirants. Journal of Higher Education, 82(5), 564

Chartrand, T. L., \& Bargh, J. A. (1999). The chameleon effect: The perception-behavior link and social interaction. Journal of Personality and Social Psychology, 76(6), 893-910.

Chemers, M. M., Zurbriggen, E. L., Syed, M., Goza, B. K., \& Bearman, S. (2011). The role of efficacy and identity in science career commitment among underrepresented minority students. Journal of Social Issues, 67(3), 469-491. doi: 10.1111/j.1540-4560.2011.01710.x

Chen, H. L., Lattuca, L. R., \& Hamilton, E. R. (2008). Conceptualizing engagement: Contributions of faculty to student engagement in engineering Journal of Engineering Education, 97(3), 339-353.

Cialdini, R. B., \& Goldstein, N. J. (2004). Social influence: Compliance and conformity. Annual Review of Psychology, 55, 591-621.

Cialdini, R. B., \& Trost, M. R. (1998). Social influence: Social norms, conformity and compliance. In Gilbert, D. T., Fiske, S. T., \& Lindzey, G. (Eds.), The handbook of social psychology (4th ed.) (Vol. 2) (pp. 151-192). Boston: McGraw-Hill.

Collins, L. M., Schafer, J. L., \& Kam, C.-M. (2001). A comparison of inclusive and restrictive strategies in modern missing data procedures. Psychological Methods, 6(4), 330-351.

Council on Graduate Medical Education. (2005). Minorities in medicine: An ethnic and cultural challenge for physician training. Rockville, MD.

Crisp, G., \& Cruz, I. (2009). Mentoring college students: A critical review of the literature between 1990 and 2007. Research in Higher Education, 50(6), 525-545.

Delgado, R., \& Stefancic, J. (2012). Critical race theory: An introduction. New York: New York University Press.

DePass, A., \& Chubin, D. (Eds.) (2009). Understanding interventions that encourage minorities to pursue research careers: Building a community of research and practice. Bethesda, MD: American Society for Cell Biology.

Dreher, G. F., \& Ash, R. A. (1990). A comparative study of mentoring among men and women in managerial, professional, and technical positions. Journal of Applied Psychology, 75(5), 539-546. doi: 10.1037/ 0021.9010 .75 .5 .539

Durik, A. M., Vida, M., \& Eccles, J. S. (2006). Task values and ability beliefs as predictors of high school literacy choices: A developmental analysis. Journal of Educational Psychology, 98(2), 382-393.

Eby, L. T., Allen, T. D., Hoffman, B. J., Baranik, L. E., Sauer, J. B., Baldwin, S., ... Evans, S. C. (2013). An interdisciplinary meta-analysis of the potential antecedents, correlates, and consequences of protégé perceptions of mentoring. Psychological Bulletin, 139(2), 441-476. doi: 10.1037/a0029279

Eby, L. T., Rhodes, J. E., \& Allen, T. D. (2007). Definition and evolution of mentoring. In Allen, T. D., \& Eby, L. T. (Eds.), The Blackwell handbook of mentoring: A multiple perspectives approach (pp. 7-20). Oxford, UK: Blackwell.

Eccles, J. S., \& Wigfield, A. (2002). Motivational beliefs, values, and goals. Annual Review of Psychology, 53(1), 109-132.

Enders, C. K. (2010). Applied missing data analysis. New York: Guilford

Estrada, M. (2014). Ingredients for improving the culture of STEM degree attainment with co-curricular supports for underrepresented minority students. (Commissioned paper for National Academies of Science, Engineering and Medicine). Retrieved January 13, 2017, from https://sites .nationalacademies.org/cs/groups/dbassesite/documents/webpage/ dbasse_088832.pdf

Estrada, M., Burnett, M., Campbell, A. G., Campbell, P. B., Denetclaw, W. F., Gutiérrez, C. G., ... Zavala, M. (2016). Improving underrepresented minority student persistence in STEM. CBE-Life Sciences Education, 15(3), es5. doi: 10.1187/cbe.16-01-0038

Estrada, M., Woodcock, A., Hernandez, P. R., \& Schultz, P. (2011). Toward a model of social influence that explains minority student integration into the scientific community. Journal of Educational Psychology, 103(1), 206-222. doi: 10.1037/a0020743
Flaxman, E., Ascher, C., \& Harrington, C. (1988). Youth mentoring: Programs and practices. New York: ERIC Clearinghouse on Urban Education.

Gándara, P., \& Maxwell-Jolly, J. (1999). Priming the pump: Strategies for increasing the achievement of underrepresented minority undergraduates. New York: College Board.

Gibbs, K. D., \& Griffin, K. A. (2013). What do I want to be with my PhD? The roles of personal values and structural dynamics in shaping the career interests of recent biomedical science PhD graduates. CBE-Life Sciences Education, 12(4), 711-723.

Green, S. B., \& Babyak, M. A. (1997). Control of type I errors with multiple tests of constraints in structural equation modeling. Multivariate Behavioral Research, 32(1), 39-51. doi: 10.1207/s15327906mbr3201_2

Hackett, G., Betz, N. E., Casas, J. M., \& Rocha-Singh, I. (1992). Gender, ethnicity, and social cognitive factors predicting the academic achievement of students in engineering. Journal of Counseling Psychology, 39, 527538.

Hancock, G. R. (1999). A sequential Scheffé-type respecification procedure for controlling type I error in exploratory structural equation model modification. Structural Equation Modeling: A Multidisciplinary Journal, 6(2), 158-168. doi: 10.1080/10705519909540126

Hausmann, L. R. M., Schofield, J. W., \& Woods, R. L. (2007). Sense of belonging as a predictor of intentions to persist among African American and white first year college students. Research in Higher Education, 48(7), 803-839.

Hu, L., \& Bentler, P. M. (1999). Cutoff criteria for fit indices in covariance structure analysis: Conventional criteria versus new alternatives. Structural Equation Modeling, 6(1), 1-55. doi: 10.1080/10705519909540118

Hurtado, S., Cabrera, N. L., Lin, M. H., Arellano, L., \& Espinosa, L. L. (2009). Diversifying science: Underrepresented student experiences in structured research programs. Research in Higher Education, 50(2), $189-214$.

Jacobi, M. (1991). Mentoring and undergraduate academic success: A literature review. Review of Educational Research, 61(4), 505-532.

Johnson, W. B., Rose, G., \& Schlosser, L. Z. (2007). Student-faculty mentoring: Theoretical and methodological issues. In Allen, T. D., \& Eby, L. T. (Eds.), The Blackwell handbook of mentoring: A multiple perspectives approach (pp. 49-69). Oxford, UK: Blackwell.

Jones, M. T., Barlow, A. E., \& Villarejo, M. (2010). Importance of undergraduate research for minority persistence and achievement in biology. Journal of Higher Education, 81(1), 82-115.

Kelman, H. C. (1958). Compliance, identification, and internalization: Three processes of attitude change. Journal of Conflict Resolution, 2, 51-60.

Kelman, H. C. (1961). Processes of opinion change. Public Opinion Quarterly, 25(1), 57-78

Kelman, H. C. (1963). The role of the group in the induction of therapeutic change. International Journal of Group Psychotherapy, 13(4), 399-451.

Kelman, H. C. (1974). Social influence and linkages between the individual and the social system: Further thoughts on the processes of compliance, identification, and internalization. In Tedeschi, J. T. (Ed.), Perspectives on social power (pp. 125-171). Chicago: Aldine.

Kelman, H. C. (2006). Interests, relationships, identities: Three central issues for individuals and groups in negotiating their social environment. Annual Review of Psychology, 57, 1-26.

Kelman, H. C., \& Hamilton, V. L. (1989). Crimes of obedience. New Haven, CT: Yale University Press.

Kram, K. (1985). Mentoring at work. Glenview, IL: Scott Foresman.

Laursen, S., Hunter, A.-B., Seymour, E., Thiry, H., \& Melton, G. (2010). Undergraduate research in the sciences: Engaging students in real science. San Francisco: Wiley.

Lent, R. (2007). Social cognitive career theory: What attracts students to-and keeps them in STEM fields? A theoretical perspective. In Understanding interventions that encourage minorities to pursue research careers: Summary of a workshop (pp. 7-11). Washington, DC: National Academies Press.

Lent, R. W., Brown, S. D., Brenner, B., Chopra, S. B., Davis, T., Talleyrand, R., \& Suthakaran, V. (2001). The role of contextual supports and barriers in the choice of math/science educational options: A test of social cognitive hypotheses. Journal of Counseling Psychology, 48(4), 474-483. 
Lent, R. W., Brown, S. D., Sheu, H.-B., Schmidt, J., Brenner, B. R., Gloster, C. S., ... Lyons, H. (2005). Social cognitive predictors of academic interests and goals in engineering: Utility for women and students at historically Black universities. Journal of Counseling Psychology, 52(1), 84-92.

Leonardo, Z. (2012). The race for class: Reflections on a critical race class theory of education. Educational Studies, 48(5), 427-449. doi: 10.1080/ 00131946.2012 .715831

Lewis, B. F. (2003). A critique of the literature on the underrepresentation of African Americans in science: Directions for future research. Journal of Women and Minorities in Science and Engineering, 9, 361-373.

Little, R. J. A. (1988). A test of missing completely at random for multivariate data with missing values. Journal of the American Statistical Association 83(404), 1198-1202. doi: 10.1080/01621459.1988.10478722

Litzler, E., Samuelson, C. C., \& Lorah, J. A. (2014). Breaking it down: Engineering student STEM confidence at the intersection of race/ethnicity and gender. Research in Higher Education, 55(8), 810-832.

Lopez, F. G., Lent, R. W., Brown, S. D., \& Gore, P. A. (1997). Role of social-cognitive expectations in high school students' mathematics-related interest and performance. Journal of Counseling Psychology, 44(1), 44-52.

Luzzo, D. A., Hasper, P., Albert, K. A., Bibby, M. A., \& Martinelli, E. A., Jr. (1999). Effects of self-efficacy-enhancing interventions on the math/ science self-efficacy and career interests, goals, and actions of career undecided college students. Journal of Counseling Psychology, 46(2), 233-234.

MacKinnon, D. P. (2008). Computer intensive methods for mediation models. In MacKinnon, C. (Ed.), Introduction to statistical mediation analysis (pp. 325-346). New York: Taylor \& Francis.

MacKinnon, D. P., Fairchild, A. J., \& Fritz, M. S. (2007). Mediation analysis. Annual Review of Psychology, 58, 593-614. doi: 10.1146/annurev .psych.58.110405.085542

Mackinnon, D. P., Lockwood, C. M., \& Williams, J. (2004). Confidence limits for the indirect effect: Distribution of the product and resampling methods. Multivariate Behavioral Research, 39(1), 99-128. doi: 10.1207/ s15327906mbr3901_4

Murphy, M. C., Steele, C. M., \& Gross, J. J. (2007). Signaling threat: How situational cues affect women in math, science, and engineering settings. Psychological Science, 18(10), 879-885.

Muthén, L., \& Muthén, B. (1998-2009). Mplus (Version 5.21). Los Angeles, CA: Muthén \& Muthén.

Nakkula, M. J., \& Harris, J. T. (2013). Assessing mentoring relationships. In DuBois, D. L., \& Karcher, M. J. (Eds.), Handbook of youth mentoring (pp. 100-117). Thousand Oaks, CA: Sage.

National Academies of Sciences, Engineering, and Medicine. (2016). Barriers and opportunities for 2-year and 4-year STEM degrees: Systemic change to support students' diverse pathways. Washington, DC: National Academies Press.

National Academies of Sciences, Engineering, and Medicine. (2017). Undergraduate research experiences for STEM students: Successes, challenges, and opportunities. Washington, DC: National Academies Press.

National Center for Education Statistics. (2005). Digest of education statistics. Retrieved June 30, 2008, from https://nces.ed.gov/programs/digest/ d05/tables/dt05_009.asp

National Research Council. (2005). Assessment of NIH minority research and training programs: Phase 3. Washington, DC: National Academies Press.
National Science Foundation, National Center for Science and Engineering Statistics. (2013). Women, minorities, and persons with disabilities in science and engineering: 2013 (Special Report NSF 13-304). Arlington, VA: National Science Foundation.

Nolan, J., Kenefick, J., \& Schultz, P. (2011). Normative social influence is underdetected by energy experts...unless you show them the data. Social Influence, 6, 169-180. doi: 10.1080/ 15534510.2011.584786

President's Council of Advisors on Science and Technology. (2012). Engage to excel: Producing one million additional college graduates with degrees in science, technology, engineering, and mathematics. Retrieved August 16, 2017, from https://obamawhitehouse.archives.gov/sites/ default/files/microsites/ostp/pcast-engage-to-excel-final_2-25-12.pdf

Ragins, B. R. (2010). Relational mentoring: A positive approach to mentoring at work. In Cameron, K. S., \& Spreitzer, G. M. (Eds.), The handbook of positive organizational scholarship (pp. 519-536). New York: Oxford University Press.

Rhodes, J. E. (2005). A model of youth mentoring. In DuBois, D. L., \& Karcher, M. J. (Eds.), Handbook of youth mentoring (pp. 30-43). Thousand Oaks, CA: Sage.

Schafer, J. L., \& Graham, J. W. (2002). Missing data: Our view of the state of the art. Psychological Methods, 7(2), 147-177. doi: 10.1037//1082 $-989 \times .7 .2 .147$

Schultz, P. W., Hernandez, P. R., Woodcock, A., Estrada, M., Chance, R. C. Aguilar, M., \& Serpe, R. T. (2011). Patching the pipeline reducing educational disparities in the sciences through minority training programs. Educational Evaluation and Policy Analysis, 33(1), 95-114. doi: 10.3102/ 0162373710392371

Schultz, P. W., Nolan, J. M., Cialdini, R. B., Goldstein, N. J., \& Griskevicius, V. (2007). The constructive, destructive, and reconstructive power of social norms. Psychological Science, 18(5), 429-434.

Schwartz, S. H. (1999). A theory of cultural values and some implications for work. Applied Psychology, 48(1), 23-47.

Schwartz, S. H., Melech, G., Lehmann, A., Burgess, S., Harris, M., \& Owens, V. (2001). Extending the cross-cultural validity of the theory of basic human values with a different method of measurement. Journal of Cross Cultural Psychology, 32(5), 519-542. doi: 10.1177/0022022101032005001

Shrout, P. E., \& Bolger, N. (2002). Mediation in experimental and nonexperimental studies: New procedures and recommendations. Psychological Methods, 7, 422-455. doi: 10.1037/1082-989X.7.4.422

Steele, C. M. (1997). A threat in the air: How stereotypes shape intellectual identity and performance. American Psychologist, 52(6), 613-629. PubMed: 9174398

Tenenbaum, H. R., Crosby, F. J., \& Gliner, M. D. (2001). Mentoring relationships in graduate school. Journal of Vocational Behavior, 59(3), 326-341. doi: 10.1006/jvbe.2001.1804

Thiry, H., \& Laursen, S. L. (2011). The role of student-advisor interactions in apprenticing undergraduate researchers into a scientific community of practice. Journal of Science Education and Technology, 20(6), 771-784.

Thompson, B. (2004). Ten commandments of structural equation modeling In Grimm, L. G., \& Yarnold, P. R. (Eds.), Reading and understanding more multivariate statistics (pp. 261-284). Washington, DC: American Psychological Association.

Villarejo, M., \& Barlow, A. E. (2007). Evolution and evaluation of a biology enrichment program for minorities. Journal of Women and Minorities in Science and Engineering, 13(2), 119-144. 